\title{
MEASURES OF SHIFTS IN REGIONAL RETAIL TRADE
}

\author{
David R. Senf*
}

The reversal of economic growth in many rural areas during the 1980 s has renewed interest in the economic vitality and development of rural areas. One highly visible gauge of rural economic health, that has drawn attention in the past and is again is rural retail trade activity (Johansen and Fuguitt; Hassinger; Ginder, Stone and Otto). In several recent studies of retail trade, the longstanding trend of declining retail trade in small- and medium-size communities has been shown to have accelerated during the 1980s. (Stone; Stinson and Sigalla; Leistritz, Bastow-Shoop and Ekstrom). Lower farm incomes and the substantial losses in wealth associated with falling farmland values have been suggested as factors contributing to the acceleration of the decline in rural retail sales. But the decrease in rural retail trade has not been limited to farming communities and it has been severe enough in many farm-centered communities to suggest additional reasons. Other likely causes include lower incomes from non-farm sources and shifting patterns of consumption behavior as to goods purchased and the purchase locations.

In this paper a new measure or index of retail trade is developed to measure the extent and direction of spatial shifts in retail trade. The index, based on the concepts of market share and concentration, yields static and dynamic measures of shifting retail trade patterns that supplement other retail trade indicators such as pull factors, leakage measures, and per capita sales figures commonly used to analyze intertemporal trade shifts. The technique introduced also is used to judge the relative influence of rural income growth and shifting spatial shopping patterns on the decline in rural retail trade. This is achieved by comparing changes in retail sales and income concentration indexes. Both indexes are calculated from community-level data. Past retail trade research has tended to use community-level retail sales but county-level income data.

The empirical evidence presented suggests that the recent decrease in rural retail trade has been due more to shifts in spatial shopping patterns than to declining rural retail purchasing power. This implies that the declines in

\footnotetext{
"Research Fellow, Department of Agricultural and Applied Economics, University of Minnesota. Most of this study was funded by the Center for Urban and Rural Affairs, University of Minnesota. The author extends his appreciation to the reviewers for their suggestions.
}

rural retail sales primarily are structural rather than cyclical. Shifting shopping patterns represent structural change, while declining rural purchasing power, arising from lower relative income growth in rural areas, may be more cyclical than structural. While the results are not particularly surprising, the procedure developed easily can be used to track future shifts in rural retail trade.

\section{Analytical Framework}

By treating each community in an appropriately delineated retail market area as a separate retail center, a measure of retail trade concentration can be developed. The measure, commonly referred to as a Herfindahl index, has been used widely in industry and market studies usually to analyze monopolistic behavior. Here the index is used to judge the relative performance of retail centers or communities of different sizes. The index is defined as;

$$
\mathrm{HI}=\Sigma \mathrm{S}_{\mathrm{i}}^{2}
$$

where $S_{i}$ is the market share of the ith community in area a given year and $\mathrm{n}$ is the number of retail centers in the market area. ${ }^{1}$

$$
\begin{aligned}
& \text { The index can be rewritten as; } \\
& \qquad \mathrm{HI}=\Sigma s_{i}+1 / n
\end{aligned}
$$

where $s_{\mathrm{i}}$ is the deviation of the share of market area retail sales of the ith trade center or community from the mean market share. ${ }^{2}$ Since $n$, the number of communities, remains constant over time the index varies only in response to changes in variation of market shares as revealed by changing $s_{i}$ values.

As communities with above-average market shares gain trade, or communities with below-average market shares lose trade, market share variation increases as does the index. The index will decrease when market share variation diminishes as would occur if communities with above-average market shares were losing trade and communities with below-average market shares were gaining trade. At its extreme the index will vary between 1 and $1 / n$, with 1 being the case in which all retail trade occurs in one community and $1 / n$ being the case in which retail trade is divided equally among all communities.

The Herfindahl index based on community retail market shares is a static measure of retail trade structure that, by itself, provides limited information and insight into changes in trade patterns. An increase in the index over 
time indicates increasing concentration of retail trade activity but it does not reveal where the shifts in trade are occurring. An increasing index may result from retail trade gains in one or several dominant trade centers. The increase also may result from a number of small trade centers capturing sales from other small trade centers. Other interpretations are equally valid without further information. The required additional information can be provided by deriving dynamic measures of concentration estimated through simple linear regression of two years of market share data.

If $Y_{i}$ is the terminal or most recent retail market share and $X_{i}$ is the base or earlier retail market share, for community $i$, then slope coefficient $b_{1}$, estimated by regressing $\mathrm{X}_{\mathrm{i}}$ on $\mathrm{Y}_{\mathrm{i}}$, will yield information about market shares changes between the two time periods. If there has been little change in market shares, $b_{1}$ will be close to one. An increase in the market share of communities with above-average market shares in the base year will yield $b_{1}$ estimates greater than one while declining market shares for communities with above-average market shares in the base year will produce $b_{1}$ values below one.

This can be seen by writing the slope estimate in deviation form;

$$
b_{1}=\frac{\Sigma\left(Y_{i}-\frac{1}{n}\right) *\left(X_{i}-\frac{1}{n}\right)}{\Sigma\left(X_{i}-\frac{1}{n}\right)^{2}}
$$

where $1 / n$, the reciprocal of the number of communities, is the mean market share for any year since the sum of market shares is one. With no change in market shares, $Y_{i}$ will equal $X_{i}$ and $b_{1}$ will be equal to one. If above-average-size trade centers are gaining shares $\left(Y_{i}-1 / n\right) *\left(X_{i}-1 / n\right)$ will be larger than $\left(\mathrm{X}_{\mathrm{i}}-1 /{ }_{\mathrm{n}}\right)^{2}$ for affected above-average- and belowaverage-size trade centers leading to $b_{1}>1$. When aboveaverage size trade centers are losing market shares, $\left(Y_{i}-1 / n\right) *\left(X_{i}-1 / n\right)$ will be smaller than $\left(X_{i}-1 / n\right)^{2}$ for affected above-average- and below-average-size trade centers thereby yielding $b_{1}<1$.

The value of $b_{1}$ will be less than or greater than one depending on whether the market shares of trade centers moving toward the mean market share were larger or smaller in the initial year than the market shares of trade centers moving away from the mean. The $b_{1}$ coefficient is a dynamic measure of shifts in retail trade patterns that can be tested for statistical significance. With $\mathrm{n}$ large enough, the value of $\left(b_{1}-1\right)$ can be interpreted as the percentage increase or decrease in the market share of the aboveaverage-size trade centers.

Further insights into the direction of the shifts in retail trade can be obtained when $b_{1}$ is rewritten in the product-momement form;

$$
b_{1}=r * Q_{y} / Q_{x}
$$

where $r$ is the coefficient of correlation between market shares in years $y$ and $x$ and the $Q_{i}$ are standard deviations of market shares in each year. If $n$ is relatively large $b_{1}$ can be approximated as follows;

$$
b_{1} \approx r * C H
$$

where $\mathrm{CH}$ is the square root of the ratio comparing retail trade concentration indexes $(\mathrm{HI})$ between the terminal and base years.

This approximation is valid since,

$$
\sqrt{\frac{Q_{y}}{Q_{x}}}=\sqrt{\frac{\Sigma y_{i}^{2}}{\Sigma x_{i}^{2}}} \approx \sqrt{\frac{\Sigma y_{i}^{2}+1 / n}{\Sigma x_{i}^{2}+1 / n}}=\sqrt{\frac{H_{y}}{H_{x}}}
$$

where $y_{i}$ and $x_{i}$ are market share deviations. The correlation coefficient, $r$, provides information on the degree of correlation between market shares in the two years. The lower the value of $r$, the more trade has shifted between trade centers. $\mathrm{CH}$ indicates the direction and magnitude of concentration change. If $\mathrm{CH}$ is greater (less) than one then retail trade concentration has increased (decreased). When examined together, $\mathrm{r}$ and $\mathrm{CH}$ reveal which size markets, on average, are gaining and losing trade.

The $b_{1}$ coefficient will be larger than one when $r \approx$ 1 and $\mathrm{CH}>1$, indicating that retail trade is increasing in larger markets at the expense of smaller markets. $A b_{1}$ less than one results if either $\mathrm{r}$ or $\mathrm{CH}$ is less than one or if both are. When $\mathrm{r} \approx 1$ and $\mathrm{CH}<1$, there is evidence of loss of sales by larger trade centers to smaller trade centers. If $r<1$ and $\mathrm{CH} \approx 1$, larger trade centers are shifting trade among themselves. Larger trade centers are losing trade to each other and to smaller trade centers when both $\mathrm{r}$ and $\mathrm{CH}$ are less than one.

\section{Application}

Similar to trends in other states, expansion of retail trade in small- and medium-size Minnesota communities has lagged compared to larger communities during the 1980s (Senf and Anding). The retail trade concentration measures reported in Tables 1 and 2 confirm the trend of increasing retail sales concentration and aid in determining the causes. ${ }^{3}$ Fourteen retail market configurations, representing different delineations of market areas within the state were utilized in this study. The first area, labeled Minnesota, treated the entire state as one large retail market. Another delineation, termed Greater Minnesota, included all of the state except the Minneapolis/St. Paul metropolitan area. The other areas correspond to the economic development regions of Minnesota and vary in size from four to nine counties.

As is true in many regional or spatially oriented analyses, lack of data on interregional flows, in this case on 
Table 1

Retail Sales Concentration Indexes for Minnesota Market Areas, 1979-1987

\begin{tabular}{lccccccccccc}
\hline \hline Market Area & $\mathrm{n}$ & 1979 & 1980 & 1981 & 1982 & 1983 & 1984 & 1985 & 1986 & 1987 & Ratio* \\
\hline Minnesota & 2492 & 3141.6 & 3098.3 & 3056.5 & 3166.7 & 3370.8 & 3537.6 & 3659.2 & 3897.3 & 3960.5 & 1.24 \\
Greater MN & 2491 & 151.3 & 145.0 & 145.1 & 147.5 & 162.4 & 170.1 & 173.0 & 188.1 & 190.1 & 1.25 \\
Region 1 & 283 & 910.2 & 901.9 & 950.7 & 963.7 & 864.0 & 913.0 & 939.0 & 950.5 & 1030.1 & 1.06 \\
Region 2 & 128 & 2941.3 & 3070.9 & 3159.5 & 3441.2 & 3472.2 & 3436.6 & 3303.5 & 3397.9 & 3475.6 & 1.11 \\
Region 3 & 275 & 2066.5 & 2016.5 & 1776.1 & 1786.1 & 1895.4 & 1927.6 & 1947.9 & 2069.7 & 2125.1 & 1.05 \\
Region 4 & 323 & 910.6 & 910.7 & 887.3 & 897.8 & 948.9 & 966.4 & 999.1 & 1045.1 & 1042.3 & 1.14 \\
Region 5 & 222 & 1408.4 & 1370.2 & 1347.8 & 1305.3 & 1284.9 & 1364.2 & 1374.1 & 1491.3 & 1424.9 & 1.04 \\
Region 6E & 121 & 1189.9 & 1272.1 & 1219.4 & 1288.1 & 1376.8 & 1442.8 & 1531.1 & 1544.3 & 1561.4 & 1.26 \\
Region 6W & 132 & 954.9 & 903.4 & 936.8 & 993.0 & 1273.9 & 1404.8 & 1423.9 & 1308.3 & 1398.3 & 1.48 \\
Region 7E & 139 & 813.5 & 782.8 & 773.4 & 779.7 & 785.6 & 788.9 & 762.8 & 756.4 & 762.6 & 0.96 \\
Region 7W & 129 & 1938.7 & 2003.3 & 2270.5 & 2146.8 & 2416.9 & 2341.2 & 2380.4 & 2593.6 & 2550.1 & 1.21 \\
Region 8 & 245 & 699.5 & 727.2 & 724.6 & 746.6 & 810.5 & 851.4 & 875.7 & 941.4 & 984.5 & 1.30 \\
Region 9 & 225 & 1106.3 & 1140.5 & 1165.3 & 1120.5 & 1162.8 & 1258.5 & 1358.2 & 1407.5 & 1455.9 & 1.24 \\
Region 10 & 269 & 1051.2 & 1081.5 & 1106.6 & 1144.9 & 1219.7 & 1322.2 & 1266.9 & 1357.2 & 1393.3 & 1.24 \\
\hline \hline
\end{tabular}

*Ratio is the average of 1985-1987 indexes divided by the average of 1979-1981 indexes.

retail trade flows, created study area delineation problems. The 14 market areas utilized here are at best proxies for actual retail market areas. The economic development regions used to draw trade market boundaries were developed during the late 1960s (Hoyt). The boundaries, which were based partially on the hierarchy of trade and service centers at that time, represent the most logical current market boundaries, given the lack of more recent information on retail trade flows. In each of the sub-state areas there is a hierarchy of trade centers consistent with central place theory. Each regional market contains at least one major retail trade center offering the full array of retail establishments plus a number of successively lower-order trade centers. Driving time from anywhere in the trade area to a major trade center is under an hour in most instances.

The second column of Table 1 lists the number of cities, towns, hamlets and townships comprising the various trade areas. These geographic units correspond with the Census Series P-26 geographic division of the state. The metropolitan area is treated as one large trade center here, thus for the trading area defined as the entire state there are 2,492 geographic units; for the Greater Minnesota trading area there are 2,491 geographic units. Only a third of the geographic units actually are locations of retail trade activity. These locations are cities, towns and hamlets (referred to here as retail trade centers) for which retail sales data is available. The other geographic units are the hinterlands surrounding the trade centers; these have little if any retail trade activity. Use of this detailed partition permits comparisons of shifts in retail trade and income.

To facilitate interpretation of the concentration indexes in Table 1, each index (calculated using equation
(1) and defining market shares as percent of community retail sales divided by total retail market sales) was multiplied by 10,000 . Since the numbers of geographic units and trade centers vary across the market area the extreme values of the indexes vary. This makes inter-market comparisons of concentration based on differences among indexes invalid. The range of values for each index is 10,000 to $10,000 /$, with 10,000 the value when all retail trade occurs in one trade center and $10,000 / \mathrm{n}$ the value when the retail trade is spread equally across all trade centers. The indexes are relatively sensitive to changes in retail market shares. A 1 percent drop in the market share of the largest trade center outside the metropolitan area (Duluth) would change the Greater Minnesota index from 151.3 to 150.4 if the lost trade were spread equally across surrounding communities.

The retail sales concentration indexes in Table 1 reveal that retail trade became increasingly concentrated in Minnesota between 1979 and 1987. In all but one market area, the exception being Region 7E, the 1987 retail trade concentration index exceeds the 1979 index. The evidence of increased concentration is reinforced by comparing the average index for the last three years to the average index during the first three years, as is done by the ratios in the last column of Table 1. In most of the trade areas the trend toward higher concentration has been steady, as evidenced by the preponderance of annual increases in the indexes.

There were, however, a number of years when the indexes fell. An explanation for the falling indexes is not readily apparent. Decreasing indexes during 1981-82 may have reflected the recession. One would except consumers to reduce purchases of durable goods during a recession. 
Since the availability of durable goods is more concentrated than that of other retail goods, lower durable goods spending would tend to decrease overall retail trade concentration. Some of the variation may be due to poor data. The retail sales data used have been revised recently to improve reliability, but collection errors may remain. The area where retail trade concentration has been decreasing, Region 7E is adjacent to the metropolitan area. Residential growth in this region apparently is dispersing retail activity.

The conclusion that retail trade concentration is rising is bolstered by examining the estimates of $b_{1}$ for the market areas. Estimates of $b_{1}$ and of $r$ and $\mathrm{CH}$ are shown in Table 2. As indicated above, an increase in a retail trade concentration index could arise from shifts in trade between small trade centers as well as shifts of trade from small to larger centers. The dynamic measures of retail trade concentration $\left(b_{1}, r, C H\right)$ shown in Table 2 provide additional information from which the direction and magnitude of shifts in retail trade can be determined unambiguously. The regression results summarized in Table 2 are for the linear relationship;

$$
\mathrm{Y}_{\mathrm{i}}=\mathrm{b}_{\mathrm{o}}+\mathrm{b}_{1} * \mathrm{X}_{\mathrm{i}}
$$

where $Y_{i}$ and $X_{i}$ are the 1987 and 1979 retail market shares of community or trade center $i$.

In 11 of the market areas the $b_{1}$ estimates were greater than one, implying that the increased concentration of retail trade resulted because the larger trade centers increased their market shares. The $b_{1}$ estimates for Regions 1 and 5 were not significantly different from one, implying no change in trade concentration. In Region $7 \mathrm{E}$, the $\mathrm{b}_{1}$ estimate was significantly less than one, indicating a reduction in trade concentration. Since both the $\mathrm{r}$ and $\mathrm{CH}$ values for Region 7E were less than one, there is evidence that retail trade shifted among large retail trade centers as well as to smaller trade centers.

In the regions where the $b_{1}$ estimates were significantly greater than one, the $\left(b_{1}-1\right)$ values can be interpreted as the average percentage increase in retail market shares by above-average-size trade centers during 1979-87, with above-average size determined by 1979 sales. For example, the $b_{1}$ estimate for the Greater Minnesota market area was 1.0764 . This implies that on average, aboveaverage-size trade centers outside of the metropolitan area increased their retail market shares by 7.6 percent between 1979-1987.

Developing income-based concentration indexes for the 14 market areas and comparing changes in income and retail trade indexes, provide insight into the relative influence of income changes and shifting shopping patterns on retail trade patterns. If the shifts in the spatial income distribution are similar to the spatial shifts in retail trade, there is evidence that the increasing trade concentration is income induced. That is, slower income growth in

Table 2

Dynamic Retail Sales Concentraion Measures

\begin{tabular}{lrrrrrr}
\hline Market Area & $\mathbf{n}$ & $\mathbf{b}$ & $\begin{array}{c}\text { standard } \\
\text { error }\end{array}$ & $\begin{array}{c}\mathrm{t} \\
\text { statistic* }\end{array}$ & $\mathbf{r}$ & $\mathrm{CH}$ \\
\hline Minnesota & 2492 & 1.1234 & 0.0007 & 185.0 & 0.9996 & 1.1228 \\
Greater Minnesota & 2491 & 1.0764 & 0.0065 & 11.8 & 0.9576 & 1.1209 \\
Region 1 & 283 & 0.9769 & 0.0255 & -0.9 & 0.9162 & 1.0638 \\
Region 2 & 128 & 1.0858 & 0.0078 & 10.9 & 0.9967 & 1.0870 \\
Region 3 & 275 & 1.0124 & 0.0038 & 3.3 & 0.9981 & 1.0141 \\
Region 4 & 323 & 1.0602 & 0.0090 & 6.7 & 0.9888 & 1.0699 \\
Region 5 & 222 & 0.9739 & 0.0170 & -1.5 & 0.9681 & 1.0058 \\
Region 6E & 121 & 1.1097 & 0.0296 & 3.7 & 0.9602 & 1.1455 \\
Region 6W & 132 & 1.1776 & 0.0301 & 5.9 & 0.9602 & 1.2101 \\
Region 7E & 139 & 0.9418 & 0.0186 & -3.1 & 0.9763 & 0.9682 \\
Region 7W & 129 & 1.1344 & 0.0172 & 7.8 & 0.9846 & 1.1469 \\
Region 8 & 245 & 1.1714 & 0.0158 & 10.9 & 0.9786 & 1.1864 \\
Region 9 & 225 & 1.1471 & 0.0078 & 18.9 & 0.9949 & 1.1472 \\
Region 10 & 269 & 1.1464 & 0.0094 & 15.6 & 0.9913 & 1.1513 \\
\hline
\end{tabular}

\footnotetext{
$*$ t statistic $=$

standard error of $b_{1}$ (retail sales)
}

$b_{1}$ (retail sales) - 1 
rural areas has reduced the retail purchasing power of rural residents and resulted in stagnant retail sales in medium and small trade centers. If the changes in income concentration differ from the changes in retail trade concentration, an argument can be made that shifting shopping patterns and not declining relative rural purchasing power, are the cause of increasing retail trade concentration.

Table 3 lists the indexes and related regression results relevant for comparing spatial shifts in retail sales and income. The slope coefficients $\left(b_{1}\right)$, were estimated using the linear relationships specified before (equation 7) with 1979 as the initial or independent year and 1985 as the terminal or dependent year. ${ }^{4}$ The terminal year was 1985 since 1987 income data were not available.

In ten of the market areas, the slope coefficient for change in retail sales concentration was significantly greater than the coefficient for change in income concentration. This suggests that in those market areas, increases in the concentration of retail sales exceeded the increases in income concentration. Spatial shifts in the income distribution have differed from the shifts in the retail sales distribution during the period. The disparity in the shifts in income and retail trade was of sufficient magnitude in some market areas to suggest that shifting shopping patterns, were the prime cause of the relative decline in retail sales in medium and small communities instead of declining relative rural income or purchasing power. During
1979-87, rural Minnesotans appear to have chosen increasingly to bypass their local trade centers and to spend their retail dollars in more distant larger retail trade centers. This conclusion is consistent with past research findings that shifting spatial shopping patterns have played a larger role in retail trade shifts than have income changes.

Differences between the $b_{1}$ estimates of changes in retail sales and income concentration in a market area can be used to gauge the relative importance of shifting spatial income distribution and shifting shopping patterns as forces of change in spatial retail sales patterns. For example, the retail sales $b_{1}$ estimate for the market area defined as the entire state, the Minnesota area, was only slightly larger than the income $b_{1}$ coefficient ( 1.0790 vs. 1.0603). The difference was greater between the retail sales and income $b_{1}$ estimates for the Greater Minnesota market area, that excluded the metropolitan area (1.0340 vs. 0.9764 ).

Since the increase in income concentration for the state of Minnesota was only slightly less than the increase in retail sales concentration, there has been only a marginal increase in metropolitan shopping by non-metropolitans. The expanded metropolitan share of retail sales was due almost entirely to the expanded share of state income in the metropolitan area. Outside of the metropolitan area, in Greater Minnesota, spatial income concentration has decreased but retail sales concentration has increased. Thus,

Table 3

Retail Sales and Income Concentration Measures

\begin{tabular}{|c|c|c|c|c|c|c|c|c|c|c|}
\hline \multirow[t]{3}{*}{ Market Area } & \multirow[t]{3}{*}{$\mathrm{n}$} & \multicolumn{4}{|c|}{$\begin{array}{c}\text { Retail Sales } \\
\end{array}$} & \multicolumn{4}{|c|}{ Income } & \multirow{3}{*}{$\stackrel{\mathrm{t}}{\text { statistic* }}$} \\
\hline & & \multicolumn{2}{|c|}{ Concentration Index } & \multirow{2}{*}{$\begin{array}{c}\mathrm{b} \\
\text { value }\end{array}$} & \multirow{2}{*}{$\begin{array}{c}\text { standard } \\
\text { error }\end{array}$} & \multicolumn{2}{|c|}{ Concentration Index } & \multirow{2}{*}{$\begin{array}{c}\mathrm{b} \\
\text { value }\end{array}$} & \multirow{2}{*}{$\begin{array}{c}\text { standard } \\
\text { error }\end{array}$} & \\
\hline & & 1979 & 1985 & & & 1979 & 1985 & & & \\
\hline Minnesota & 2492 & 3141.6 & 3659.2 & 1.0790 & 0.0006 & 3305.6 & 3716.0 & 1.0603 & 0.0002 & -79.5 \\
\hline Greater Minnesota & 2491 & 151.3 & 173.0 & 1.0340 & 0.0056 & 68.5 & 66.5 & 0.9764 & 0.0024 & -23.9 \\
\hline Region 1 & 283 & 910.2 & 939.0 & 0.9575 & 0.0204 & 371.9 & 349.4 & 0.9628 & 0.0046 & 1.1 \\
\hline Region 2 & 128 & 2941.3 & 3303.5 & 1.0588 & 0.0065 & 573.7 & 556.8 & 0.9459 & 0.0049 & -22.9 \\
\hline Region 3 & 275 & 2066.5 & 1947.9 & 0.9677 & 0.0043 & 937.9 & 946.0 & 1.0036 & 0.0026 & 13.7 \\
\hline Region 4 & 323 & 910.6 & 999.1 & 1.0465 & 0.0070 & 410.0 & 384.3 & 0.9640 & 0.0029 & -28.4 \\
\hline Region 5 & 222 & 1408.4 & 1374.1 & 0.9722 & 0.0116 & 228.5 & 221.3 & 0.9782 & 0.0041 & 1.5 \\
\hline Region 6E & 121 & 1189.9 & 1531.1 & 1.0851 & 0.0331 & 455.3 & 494.6 & 1.0475 & 0.0082 & -4.6 \\
\hline Region 6W & 132 & 654.9 & 1423.9 & 1.1899 & 0.0301 & 319.2 & 319.2 & 0.9987 & 0.0044 & -43.5 \\
\hline Region 7E & 139 & 813.5 & 372.8 & 0.9501 & 0.0149 & 157.9 & 162.3 & 1.0235 & 0.0096 & 7.7 \\
\hline Region 7W & 129 & 1938.7 & 2380.4 & 1.0947 & 0.0167 & 347.8 & 340.1 & 0.9838 & 0.0056 & -19.8 \\
\hline Region 8 & 245 & 699.5 & 875.7 & 1.1122 & 0.0112 & 269.6 & 305.9 & 1.0741 & 0.0044 & -8.6 \\
\hline Region 9 & 225 & 1106.3 & 1358.2 & 1.1075 & 0.0069 & 331.4 & 385.8 & 1.0894 & 0.0036 & -5.0 \\
\hline Region 10 & 269 & 1051.2 & 1266.9 & 1.0944 & 0.0076 & 553.0 & 585.9 & 1.0304 & 0.0027 & -23.7 \\
\hline
\end{tabular}

b1 (income) - b1 (retail sales)

"t statistic $=$

standard error of bl (income) 
shifting shopping patterns accounted for most of the retail market share gained by larger retail market centers ${ }^{5}$. Rural residents have increased their spending in regional trade centers at the expense of smaller local trade centers but have not increased their spending in the metropolitan area significantly.

\section{Summary}

A new approach to investigating shifts in rural retail trade was presented in this paper and used to analyze recent spatial changes in retail trade in Minnesota. The results presented are consistent with previous findings that decreases in retail trade in smaller trade centers were due to increasing market shares of the larger trade centers. Comparing spatial shifts in retail sales and income shed additional light on the relative importance of shifting shopping patterns and shifting spatial income distribution as determinants of declining rural retail trade. Shifting shopping patterns appear to have had more effect on rural retail trade patterns than spatial income changes.

This suggests that much of the the decline in rural retail sales has been structural rather than cyclical. Further study is needed to find out why rural residents have been shifting their retail spending to larger trade centers. Surveys of rural residents are needed to establish the importance of price and variety of available goods in retail shopping location decisions. Such information would be valuable to those interested in determining the feasibility of revitalizing small and medium trade centers.

In lieu of retail spending surveys of rural residents, the procedure employed here provided a method for analyzing retail trade shifts. Calculating retail trade and income indexes annually for Minnesota would provide a clearer picture of intrastate retail trade shifts. Plans are being made for a similar analysis using 1987 income data to see whether recovering rural incomes since 1986 have altered the concentration trend.

\section{Notes}

${ }^{1}$ The analytical framework presented here is an extension of dynamic concentration measures developed by Grossack.

${ }^{2}$ Since $s_{i}=S_{i}-1 / n$, where $1 / n$ is the mean market share and $S_{i}=$ 1 then;

$$
\begin{aligned}
& \sum \mathbf{s}_{i}{ }^{2}=\sum\left(S_{i}-1 / n\right)^{2} \\
& =\sum S_{i}^{2}-2 * 1 / n * \sum S_{i}+\sum 1 / n \\
& =\sum S_{i}{ }^{2}-1 / n \\
& \text { or } \\
& \sum s_{i}{ }^{2}+{ }^{1}=\sum S_{i}{ }^{2} \text {. }
\end{aligned}
$$

${ }^{3}$ Retail sales data were obtained from the Tax Research Office, Minnesota Department of Revenue, St. Paul, Minnesota.

${ }^{4} \mathrm{Local}$ income estimates were obtained from the Local Population Estimates, Series P-26, Bureau of the Census, U.S. Department of Commerce.

SOne weakness of the analysis is its lack of attention to retail sales generated by tourism. The appropriateness of the procedure and the validity of the results are questionable if retail sales from tourism account for a significant percentage of total retail sales.

\section{References}

Ginder, Roger G., Kenneth E. Stone, and Daniel Otto. "Impact of the Farm Crisis on Agribusiness Firms and Rural Communities," in New Dimensions of Rural Policy: Building Upon Our Heritage. Subcommittee of Agriculture and Transportation, Hearings (June 5th, 1986), pp. 298-307.

Grossack, Irvin M. "Toward an Integration of Static and Dynamic Measures of Industry Concentration," The Review of Economics and Statistics (August 1965), pp. 301-308.

Hassinger, Edward. "The Relationship of Retail-Service Patterns to Trade Center Population Change," Rural Sociology (September 1957), pp. 235-40.

Hoyt, John S. Regional Development Systems in Minnesota, Agricultural Extension Service, University of Minnesota, 1969.

Johansen, Harley E. and Glenn V. Fuguitt. "Population Growth and Retail Decline: Conflicting Effects of Urban Accessibility in American Villages," Rural Sociology (Spring 1979), pp. 24-38.

Leistritz, F. Larry, Holly E. Bastow-Shoop, and Brenda L. Ekstrom. "Smalltown Business Also Caught in Farm Financial Stress," Rural Development Perspectives (June, 1988), pp. 27-30.

Senf, Dave and Thomas Anding. "Retail Sales Trends in Minnesota," CURA Reporter (December 1988), Center for Urban and Regional Affairs, University of Minnesota.

Stinson, Thomas F. and Fiona Sigalla. "Local Economic Impacts of the Farm Crisis: Evidence from Southwest Minnesota," Report prepared for the Senate Subcommittee on Intergovemmental Relations (May 1986).

Stone, Kenneth E. "Impacts of the Farm Financial Crisis on the Retail and Service Sectors of Rural Communities," Agricultural Finance Review (Special Issue, Vol. 47, 1987), pp. 40-47.

Tax Research Office, Minnesota Department of Revenue, Historical Retail Sales Data, 1979-1987.

U.S. Census Bureau, Department of Commerce. Local Population Estimates Current Population Reports, Series P26. 